\title{
Intent to leave and absenteeism as reactions to perceived inequity: The role of psychological and social constraints
}

\author{
Nico W. Van Yperen* and Mariët Hagedoorn \\ Department of Psychology, University of Groningen, Grote Kruisstraat 2/1, 9712 TS Groningen, The Netherlands \\ Sabine A. E. Geurts \\ Department of Psychology, University of Nijmegen, The Netberlands
}

\begin{abstract}
This study shows that (1) the perception of inequity is related to intentions to withdraw, i.e. the intent to report sick and the intent to leave, and to actual absence behaviour; (2) deprived employees were less likely to leave the organization when they felt involved in their jobs; (3) deprived employees who perceived an intolerant group absence norm were less apt to report sick.
\end{abstract}

One recognized predictor variable of employee turnover and absenteeism is employees' perception of inequity (for a review: see Mowday, 1991). Equity theory (Adams, 1965) assumes that in order to determine the equitableness of the employer-employee exchange relationship, employees compare their investments and outcomes to those of relevant others, in particular their co-workers. Employees who find themselves deprived will feel tension which motivates them to restore equity. This can be achieved, among others, by permanent withdrawal in the form of turnover ('leaving the field'), and by temporary withdrawal in the form of absenteeism. In case of advantageous inequity, however, equity theory predicts that employees will increase their efforts (Mowday, 1991), i.e. advantaged employees will be less inclined to leave and to report sick, and their absence frequencies will be lower in comparison with the equitably treated and the deprived.

The main purpose of the present paper is to show that among deprived employees: (1) a high job involvement may operate as barrier to the intent to leave, and (2) an intolerant group absence norm may operate as restraining force to the intent to report sick and absence frequency. In methodologial terms, interaction effects are expected between perceptions of inequity and these psychological and social constraints.

\section{Methods}

\section{Sample and procedure}

Respondents were blue-collar workers from two virtually identical Dutch metal manufacturing plants (see also Geurts, Buunk \& Schaufeli, 1994). All participared voluntarily. Questionnaires were completed under

*Requests for reprints. 
the supervision of two on-site assistants during two hours of duty, resulting in a response rate of 80.4 per cent. The average length of absence events (duration) of 17 per cent of the total group of participants was 14 days or more. Because in The Netherlands an examination is carried out by a physician from the industrial insurance board only when the illness lasts for two weeks or more, it is reasonable to assume that the absences of these latter participants are due to chronic sickness. The exclusion of these cases with long-term illnesses resulted in a final sample of 378 Dutch male employees, with an average length of absence events of 14 days or less.

The average age of the participants was 34.8 (ranging from 19 to 59 years). The majority of the respondents had a full-time job (98.4 per cent) and were working in three shifts ( 90.7 per cent). The average absence frequency was 1.5 , and the average length of absence events was 5.0 days.

\section{Measures}

Perceived inequity. Respondents were first asked to compare themselves to others from within the company with respect to 14 job aspects, including working environment (smell, noise, heat, etc.), variety in the job, and autonomy and freedom. Next, participants responded to the summarizing question 'All things considered, how do you feel about your job compared to most other individuals from within your company?' Answers ranged from (1) I feel much better off, to (5) I feel much worse off. A strong link exists between social comparisons on specific job aspects and a global assessment of feelings of inequity (Van Yperen, Hagedoorn \& Geurts, 1994). Participants were divided into three subgroups: advantaged group (scores 1 and 2: participants who feel much better off or feel a little better off; $N=75$ ), equitably treated group (score 3: participants who feel approximately the same; $N=261$ ), and deprived group (scores 4 and 5: participants who feel a little worse off or feel much worse off; $N=32$ ).

Job involvement. This was assessed by five representative items from a questionnaire developed by Ladewig \& White (1984), including 'The most important things that happen to me involve my work' and 'I enjoy my work more than anything else I do.' Participants responded on a five-point scale, ranging from (1) completely disagree to (5) completely agree. Coefficient alpha was .69 .

Perceived group absence norm. Respondents were asked to report how tolerant co-workers were towards absences. Five possible reasons to report sick were presented. The general stem was: 'How does your work group feel about reporting sick when one of your co-workers ...' (1) 'just wants to stay at home'; (2) 'is fed up with his job'; (3) 'does not feel too well'; (4) 'has his personal reasons'; (5) 'really feels miserable'. Participants responded on a five-point scale ranging from (1) not acceptable, to (5) completely understandable. After deletion of the fifth item, coefficient alpha was acceptable: .64. Geurts, Buunk \& Schaufeli (1994) demonstrated that the items on this scale constitute a unidimensional Guttman scale, which means that most participants who indicated that the reason for absence in, for example, item two would be tolerated, also responded affirmatively to all subsequent items ( 3 and 4 ) that leave employees less freedom of choice to report sick. $A$ higher score indicates a more tolerant perceived group absence norm.

Intent to leave the organization. Perceptions of inequity, job involvement, and group norms are not variables reflecting immediate circumstances. Instead, these variables are a result of a long-term process (weeks, months, or even years). Accordingly, the corresponding intent to leave measure was: 'For some time, I have been considering changing employers'. The seven-point scale ranged from (1) completely disagree, to (7) completely agree. A meta-analysis of longitudinal studies by Steel \& Ovalle (1984) has shown that the intent to leave is the best predictor of actual turnover.

Intent to report sick. This was assessed by the same five items as the group absence norm, but with a different general stem: 'Would you report sick when ...'(1) 'you just want to stay at home', etc. The alternatives varied from (1) certainly, to (5) certainly not. Coefficient alpha (five items) was .61, and these items also formed a unidimensional Guttman scale (Geurts et al., 1994). The answers were recoded, so that a higher score represents a stronger intent to report sick.

Absence frequency. Obtained from organizational files, this is the number of times an employee reported sick (with an average duration of less than 14 days) in a period of nine months prior to, and three months after the 
survey. The frequency of short-term absences are often presumed to reflect voluntary absences better than, for example, time-lost indices (Chadwick-Jones, Brown, Nicholson \& Sheppard, 1971).

\section{Results}

Means, standard deviations and intercorrelations among demographic variables, the dependent variables, and the assumed psychological and social constraints are shown in Table 1.

With the computer program MULTIVARIANCE (Finn \& Bock, 1988), ANOVAs were carried out that are usually done prior to analyses of covariance, in which the interaction between a factor (i.e. perceived inequity) and a continuous independent variable (i.e. the 'covariate') is tested (in this case: job involvement and group absence norm, respectively). Thus, it was tested whether within the three subgroups (those who felt advantaged, equitably treated, or deprived) different relationships exist between job involvement and intent to leave, as well as between the perceived group absence norm on the one hand, and the intent to report sick and absence frequency on the other. A significant effect indicates that, for example, job involvement is more strongly related to the intent to leave among deprived employees than among advantaged employees (i.e. non-parallel regression lines; Finn, 1974).

The results reveal main effects of perceived inequity on the intent to leave, the intent to report sick, and actual absence behaviour (see Table 2). However, after controlling for age and level of education, the main effect on actual absence behaviour disappeared

Table 1. Means, standard deviations and intercorrelations of demographic variables, the dependent variables and the assumed constraints

\begin{tabular}{|c|c|c|c|c|c|c|c|c|}
\hline Variable & 2 & 3 & 4 & 5 & 6 & 7 & $M$ & $\mathrm{SD}$ \\
\hline $\begin{array}{l}\text { 1. Job involvement } \\
\text { 2. Tolerant group }\end{array}$ & $-.16 * *$ & $-.24 * *$ & $-.24 * *$ & -.09 & $.20 * *$ & .03 & 2.39 & .72 \\
\hline $\begin{array}{l}\text { absence norm } \\
\text { 3. Intent to leave }\end{array}$ & & $.22 * *$ & $.30 * *$ & .11 & -.09 & -.05 & 2.48 & .70 \\
\hline the organization & & & $.25 * *$ & .10 & $-.20 * *$ & .04 & 2.85 & 1.91 \\
\hline 4. Intent to report sick & & & & $.26 * *$ & $-.13 *$ & -.07 & 2.32 & .68 \\
\hline 5. Absence frequency & & & & & $-.28 * *$ & -.10 & 1.46 & 1.42 \\
\hline 6. Age & & & & & & .07 & 34.76 & 9.40 \\
\hline 7. Level of education & & & & & & & 2.89 & 2.22 \\
\hline
\end{tabular}

${ }^{*} p<.01 ; * * p<.001$.

Table 2. Relationships between perception of inequity and intent to leave, the intent to report sick and absence frequency

\begin{tabular}{|c|c|c|c|c|c|c|c|}
\hline & \multirow[b]{2}{*}{$F(2,361)$} & \multicolumn{2}{|c|}{ Advantaged } & \multicolumn{2}{|c|}{ Equitably treated } & \multicolumn{2}{|c|}{ Deprived } \\
\hline & & $M$ & $\mathrm{SD}$ & $M$ & SD & $M$ & $\mathrm{SD}$ \\
\hline Intent to leave & $7.54 * * *$ & 2.27 & 1.59 & 2.94 & 1.94 & 3.66 & 2.03 \\
\hline Intent to report sick & $6.17 * * *$ & 2.09 & .62 & 2.36 & .68 & 2.51 & .68 \\
\hline Absence frequency & $3.17 *$ & 1.17 & 1.33 & 1.48 & 1.44 & 1.91 & 1.49 \\
\hline
\end{tabular}

$*_{p}<.05 ; * * p<.01 ; * * * p<.001$. 
$(F(2,358)=1.70$, n.s. $)$. The multivariate main effect and the two other univariate effects were still significant at the .01 level.

After controlling for main effects, interaction effects were found of perceived inequity with job involvement on the intent to leave $(F(2,361)=5.05, p<.01)$ and perceived inequity with the group absence norm on the intent to report sick $(F(2,361)=4.12$, $p<.01)$. After controlling for age and level of education, these effects were still significant at the .01 level. No interaction was observed of perceived inequity with the group absence norm on absence frequency $(F(2,361)=.65$, n.s. $)$.

As represented by the steep slope in Fig. 1, there is a much stronger relationship between job involvement and the intent to leave among deprived employees than among the equitably treated and the advantaged. Hence, it can be concluded that job involvement acts as a psychological constraint on the intent to leave, especially for deprived employees.

The interaction between perceived inequity and the perceived group absence norm on the intent to report sick is shown in Fig. 2. Only among the equitably treated and the deprived a more tolerant group absence norm was related to a higher intent to report sick, suggesting that among these two subgroups, the group absence norm operates as a social constraint on the intent to report sick.

\section{Discussion}

The first finding of interest was the relation between the global perception of perceived inequity and intentions to withdraw, either permanently by leaving the organization or temporarily by being absent, and to actual absence behaviour, although this latter effect disappeared after controlling for age and level of education. Specifically, employees who

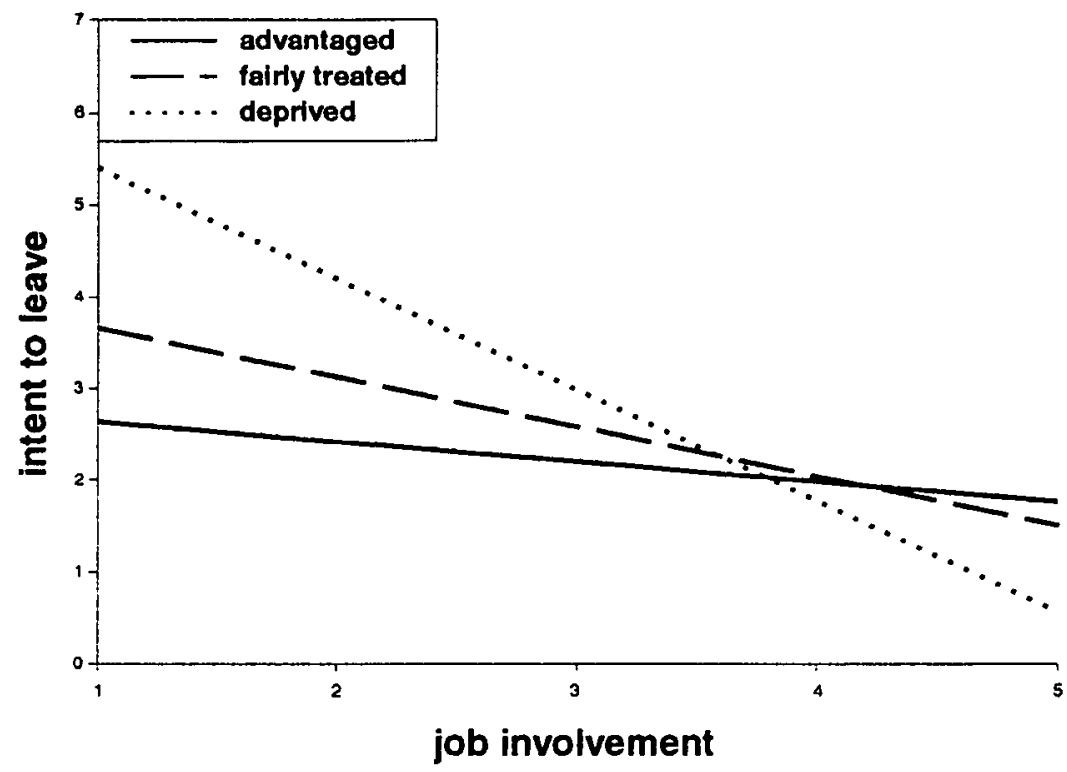

Figure 1. Interaction of perceived inequity and job involvement on intent to leave. 


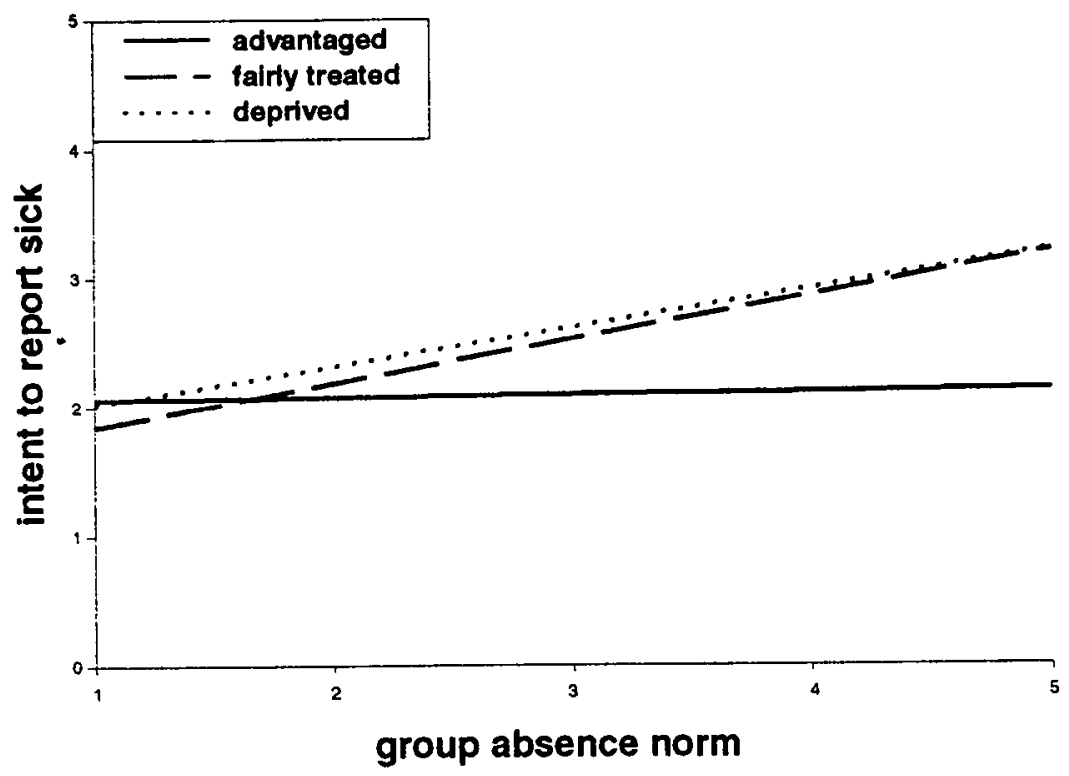

Figure 2. Interaction of perceived inequity and group absence norm on intent to report sick (a higher score indicates a more tolerant group absence norm as perceived by the individual).

felt deprived in the work situation were most apt to quit and to report sick, while those who felt advantaged reported the lowest intentions to leave and to report sick. From the perspective of equity theory, these stronger withdrawal intentions of deprived employees can be understood as attempts to reduce the tension by restoring equity (Adams, 1965). In addition, advantaged employees were less inclined to leave and to report sick, and their absence frequencies were lower in comparison with the equitably treated, which is also in line with the predictions of equity theory.

The present study further demonstrates that deprived employees were less likely to leave the organization when they felt involved in their job. Similarly, deprived employees who perceived an intolerant group absence norm were less apt to report sick. These findings suggest that in combination with perceived psychological or social constraints, perceived inequity may cause employees to choose other means of restoring equity than by withdrawing temporarily or permanently.

\section{Acknowledgement}

The authors wish to thank Bram P. Buunk for useful comments on earlier drafts of this article.

\section{References}

Adams, J. S. (1965). Inequity in social exchange. Advances in Experimental Social Psychology, 2, 267-299.

Chadwick-Jones, J. K., Brown, C. A., Nicholson, N. \& Sheppard, C. (1971). Absence measures: Their reliability and stability in an industrial setting. Personnel Psychology, 24, 463-470.

Finn, J. D. (1974). A General Model for Multivariate Analysis. New York: Holt, Rinehart \& Winston.

Finn, J. D. \& Bock, R. D. (1988). MULTIVARIANCE PC: User's Guide (Version 7.3). Chicago, IL: Scientific Software. 
Geurts, S. A., Buunk, B. P. \& Schaufeli, W. B. (1994). Social comparisons and absenteeism: A structural modeling approach. Journal of Applied Social Psychology, 24, 1871-1890.

Ladewig, B. H. \& White, P. N. (1984). Dual-earner marriages: The family social environment and dyadic adjustment. Journal of Family Issues, 5, 343-362.

Mowday, R. T. (1991). Equity theory predictions of behavior in organizations. In R. M. Steers \& L. W. Porter (Eds), Motivation and Work Behavior, pp. 111-131. New York: McGraw-Hill.

Steel, R. P. \& Ovalle, N. K. 2d (1984). A review and meta-analysis of research on the relationship between behavioral intentions and employee curnover. Journal of Applied Psychology, 69, 673-686.

Van Yperen, N. W., Hagedoorn, M. \& Geurts, S. A. (1994). Terugtrekgedrag van werknemers: Verloop en verzuim als reacties op onbillijkheid (Job withdrawal of employees: Turnover and absenteeism as renctions to inequity). Gedrag en Organisatie, 7, 243-260.

Received 20 February 1995; revised version received 18 January 1996 
Copyright of Journal of Occupational \& Organizational Psychology is the property of British Psychological Society. The copyright in an individual article may be maintained by the author in certain cases. Content may not be copied or emailed to multiple sites or posted to a listserv without the copyright holder's express written permission. However, users may print, download, or email articles for individual use. 